\title{
Prevention of HIV infection among adolescents and young people in South Kivu: challenges and prospectives
}

\author{
Bahizire Riziki Richard $^{1,2 *}$, Muciza Bayunvanye Freud ${ }^{1}$, Mandjo Aholoma J-Lambert ${ }^{3}$, \\ Aganze Mitima Synthia ${ }^{4}$, Mapendo Ndeko Fefe ${ }^{5}$, Kininga Amisi David ${ }^{1}$, \\ Ampire Bagalwa Espoir ${ }^{6}$, Rwizibuka Mugisho Binvenue ${ }^{5}$
}

\begin{abstract}
${ }^{1}$ National Multi-sectector Programme of fighting AIDS
${ }^{2}$ Department of Public Health, High College of Medical Techniques of Nyangezi

${ }^{3}$ Department of Microbiology, High College of Medical Techniques of Kinshasa

${ }^{4}$ Center for training and Study in environment, safety and health at work, Bukavu

${ }^{5}$ Department of Medecine, University of Kaziba, South-Kivu

${ }^{6}$ Teachers Training College of Bukavu
\end{abstract}

Received: 25 March 2021

Accepted: 30 April 2021

\section{*Correspondence:}

Dr. Bahizire Riziki Richard,

E-mail: brrichard79@gmail.com

Copyright: ( $)$ the author(s), publisher and licensee Medip Academy. This is an open-access article distributed under the terms of the Creative Commons Attribution Non-Commercial License, which permits unrestricted non-commercial use, distribution, and reproduction in any medium, provided the original work is properly cited.

\section{ABSTRACT}

Background : It's worldwide established that interventions to combat HIV are being carried out, but most of them target adults and leave out adolescents and young people, who constitute one of the most exposed sections of the population.

Methods : A cross-sectional and qualitative study on prevention of HIV among adolescent and young people conducted from 15 and 30 June 2019 in seven health zones of South Kivu in the democratic republic of Congo. All interviews and focus groups were transcribed in full, the obtained corpus; a thematic manual analysis was carried out. Results : Several stakeholders are involved in the fight against HIV/AIDS among adolescents and young people, in spite, available services are not sufficiently accessible to adolescents and young people due to many constraints: political, organisational, legal, economic-financial, socio-cultural and religious. Prevention services for adolescents and young people are, according to them, inadequate, insufficient and not user-friendly.

Conclusions: Stakeholders should use findings of this study as a basis for reflection for the implementation of more effective interventions for adolescents and young people to reverse the current trend of the HIV epidemic in South Kivu province.

Keywords: Prevention, HIV, adolescents, South Kivu

\section{INTRODUCTION}

According to UNICEF, adolescents aged between 10 and 19 accounts for nearly two-thirds of the 3 million people under 19 living with HIV. Some 1.2 million people aged 15-19 were living with HIV in 2017; 3 out of 5 were girls. ${ }^{1}$ In the democratic republic of Congo (DRC), six out of ten people are under 20. Most congolese adolescents engage in unprotected sex at an early age. Around $65 \%$ of this age group has already had their first sexual relations, which may explain the high HIV prevalence among adolescents: $0.5 \%$ of young people aged between 10 and 19 are HIV-positive, with a disparity between girls $(0.7 \%)$ and boys $(0.2 \%){ }^{2}$

In South Kivu, the demographic and social survey indicates that HIV prevalence was $1.7 \%$ among girls aged 15-24, more than twice as high as that of boys in the same age group $(<0.1 \%)$. HIV prevalence among adolescent and young girls in South Kivu is higher than 
the national prevalence in the same age category and sex $(1 \%){ }^{3}$ It is clear that interventions to combat HIV are being carried out, but most of them target adults and leave out adolescents and young people, who constitute one of the most exposed sections of the population.

\section{Aim and objective}

The objective of this study is to contribute to the reduction of new HIV infections among adolescents and young people in South Kivu province by making available data that can guide the various actors in the fight against the disease. More specifically, it aims at: identifying the stakeholders in the fight against HIV/AIDS among young people and adolescents in South Kivu and assess their degree of involvement; determining adolescents and young people's perceptions of the availability of HIV prevention services and proposing effective solutions for the prevention of HIV/AIDS among adolescents and young people in South Kivu province.

\section{METHODS}

Current study was a cross-sectional and qualitative study. Current study was focused on two main target groups: 28 key informants on the one hand and 70 adolescents and young people (10-19 years old) on the other; a total of 98 respondents chosen by convenience. Seven health zones (ZS) out of 34 in the province of South Kivu in the democratic republic of Congo were concerned: Ibanda, Kadutu, Bagira and Uvira for the urban part and Minova, Idjwi and Katana for the rural part.

\section{Data collection}

The data was collected from individual semi-directive indepth interviews transcribed entirely on paper and conducted between 15 and 30 June 2019. These interviews and focus groups lasted on average 45 minutes and were conducted in French or Swahili, as appropriate. Our interview guides explored the following themes: identification of stakeholders and degree of involvement, young people and adolescents' perceptions of the HIV prevention services available and suggested effective solutions for HIV/AIDS prevention among adolescents and young people.

\section{Data analysis}

All interviews and focus groups were transcribed in full. From this corpus, a thematic manual analysis was carried out. Successive readings were carried out and made it possible to identify, index and categorise the themes. The results thus obtained were compared with those of previous studies on similar subjects. Oral consent was obtained from all participants after a clear explanation of the objectives of the study and its benefits. The names of the respondents were not quoted for reasons of anonymity and confidentiality.

\section{RESULTS}

The participants in this study are aged $10-55,71.4 \%$ were aged $10-19.55 \%$ were male, and rural health areas account for $57 \%$ of the respondents. It should also be noted that $30 \%$ are out-of school adolescents and young people.

\section{Stakeholders and their level of involvement in the fight against HIV among young people and adolescents in South Kivu}

The results of this section have been presented in a (Table 2) to make the reading easier.

\section{Adolescents and young people's perception of the prevention services offered}

Services available; the majority of adolescents and young people interviewed admit that there are prevention services available in their health areas. These include awareness-raising activities, screening and condom distribution.

Sources of information; awareness-raising is done by local NGOs, churches, specialised programmes through health zones and health structures (health centres and hospitals), but also in schools through life education courses and sessions organised by peer educators. Restricted families also play an important role in this awareness raising as well as the mass media (radio and television through broadcasts and social networks: facebook, wathsapp and youtube).

The most appropriate sources in both rural and urban areas are family, radio, churches, health facilities and schools, including peer educators and social networks, the latter being much more cited by young people in urban than in rural areas.

Out-of-school youth said they are informed by family, churches, radio and local NGOs through awareness sessions. Jimy, a 16 yearold out-of-school youth from Katana, said in extension: "We don't go to school, but the AIDS issue is talked about in the family as a warning by pointing out the neighbour who has been sick with AIDS. Sometimes other young people talk to us about AIDS when they are sent by health professionals, the radio also talks about it".

\section{Messages conveyed by the different sources of information}

Churches; the content varies according to the sources of information: usually young people discuss issues of sexual and reproductive health, HIV and other STD (sexual transmitted disease) among themselves. In religious settings, young people limit themselves to issues of chastity, virginity and the possibility of marriage, so they are called upon to abstain from sex in order to 
respect moral norms and religious principles. According to our interviewees, these contents are adapted to the youngest (10-14 years old) who are not sexually active and not to those who already have a sexually active life.

"I had my first sexual intercourse when I was 13 years old, today I am 18 and I have a two year old child, I know everything about life, I am very sexually active, sometimes I live off my sex, I have friends who are as young as me, but I like older people a lot more because they know what a girl needs. For me, the teachings of the Church, I listen to them when I'm there, but frankly, they are out of fashion", said a girl from Minova.

Another adds: 'are those who invite us to abstain from sex themselves abstinent or faithful? Everyone has to make his or her own life, everyone will give an account to God, the business of sex, we have found it on earth and there is nothing we can do about it. They forbid us to do this or that practice, saying that it is not in accordance with God's will, but they are the first to run behind girls " 23 year old girl from Katana

Table 1: General characteristics of study population.

\begin{tabular}{|ll|}
\hline Parameters (n=98) & Frequency (\%) \\
\hline Age range (years) & \\
\hline $10-19$ & $70(71.4)$ \\
\hline $20-24$ & $10(10.2)$ \\
\hline $25-49$ & $13(13.3)$ \\
\hline $50-55$ & $5(5.1)$ \\
\hline Gender & \\
\hline Male & $54(55)$ \\
\hline Female & $44(45)$ \\
\hline Residence & \\
\hline Rural area & $56(57.1)$ \\
\hline Urban area & $42(42.9)$ \\
\hline Education $(\mathrm{N}=70)$ & \\
\hline In school & $49(70)$ \\
\hline Out of school & $21(30)$ \\
\hline
\end{tabular}

Families; here, sexual and reproductive health and HIV issues are implicitly addressed by parents in the form of warnings about unwanted pregnancies and AIDS. There is no real, frank dialogue about reproductive health and HIV issues.

My father always says to me: "you are already grown up, the day you are going to impregnate a girl, you will not be coming with her to my house, you have to be careful. That's what I used to tell your sister, she didn't understand anything, today she has disgraced the whole family and you can see that she is living in misery"24-year-old Kadutu.

Health structures and NGOs; the content of the health structures and NGOs is comprehensive, covering all aspects including: abstinence, good fidelity, correct and systematic use of condoms, screening and post-exposure prevention. "There are no taboo issues," said a nurse in charge of a health centre. NGOs are also on the same track and are addressing all aspects of prevention.

Media and social networks; the media and social networks also address the issue of HIV in a comprehensive but topical way.

For teachers, "the internet is a major source of information, especially during the preparation of life education classes, but you need to have a good telephone or a connected computer and know what you are really looking for," said a life education teacher from Bagira.

\section{Perception and accessibility of services offered}

Young people see sexuality issues as taboo, yet it is almost impossible to talk about HIV without talking about sexuality issues. Among adolescents, it is not always easy to talk about sexuality in public, and this is more noticeable in rural than in urban areas. Many of the young people reported that they do not have access to information because they say that HIV activities are rarely or hardly organised in their respective settings.

In both rural and urban areas, they talk about the distance between the young people who once existed and their homes. This distance is very great, ranging from 7 to more than 10 or even $15 \mathrm{~km}$ in rural areas, while in towns some say they have to pay for transport to reach a centre where they can get information on HIV/AIDS.

"I live in Panzi Kamagema, the closest centre I know where you can easily get information is at the red light. I can't reach it without having money to pay for transport. Moreover, in my school, my church and my family there is hardly any talk about AIDS. I'm satisfied with the information I can get on the radio, they too don't talk about AIDS as they used to, I wonder if the disease has disappeared, as my peers say, but I think it no longer exists because there is no longer the mobilisation that there used to be". Young student boy; 18 years old, Panzi neighbourhood.

The fear of not finding a user-friendly provider in the centres is also pointed out, or the fear of finding providers who know us: "how can I go and sit among adults and spread my concerns about HIV in public, especially when the person teaching about HIV is a member of our church or a neighbour who knows me very well? They might think I'm a prostitute, but no, it blocks us. One day, I found a father from our church in the awareness room, he told me, these stories are not about your age, whereas I have sex with other young people and sometimes with people older than me" Young girl, 16 years old, not attending school in Minova-Centre.

The attitudes of some providers, parents and church leaders: the majority of young people interviewed in both urban and rural areas felt that the attitudes of providers, 
parents and church leaders in some churches did not facilitate the fight against HIV, as evidenced by this statement from a 15 year old from Idjwi: "sometimes the nurses do not want to let us into the room where the activities are conducted, especially if the adults are there, the parents do not allow us to go too, and sometimes we have to cheat to follow the sensitisations. The pastors say that we talk about condoms and we teach the children to have sex, they are very critical".

Table 2: Stakeholders and level of involvement.

Category

Religious denominations

(Catholic, Protestant,

Kimbanguist, Muslim and

others)

\section{Observation:}

If the teachings are oriented towards the fight against fornication and adultery through abstinence and good fidelity, they do not mention condoms, which they consider contrary to religious morality. Screening is encouraged or even required before nuptial blessings. The fight against stigmatisation and discrimination of PLWHIV is included in the general teachings on love of a neighbour and does not explicitly address the issue of HIV/AIDS. Care is provided within the structures of the religious conventions, following the directives and instructions of the (National AIDS programme) PNLS.

Local NGOs and community
based organisations

Finding:

All the 15 structures represented in the study intervene in the health sector and, by extension, the fight against HIV in their missions, however, their managers declare that they do not have the resources. Their activities are currently limited to sporadic actions in the event of an activity by the multisectorial AIDS programme (PNMLS) or another partner (UNICEF, CORDAID, health area, etc.) which involves them.

\begin{tabular}{|ll}
\hline Schools & $\begin{array}{l}\text { Life education courses, awareness-raising and referral to Medium } \\
\text { health centres }\end{array}$ \\
\hline
\end{tabular}

\section{Finding:}

15 school leaders were interviewed during the study. Overall, they showed that life education course is an opportunity to talk about HIV. It is noted that 4 schools are part of the All in project and carry out screening orientation activities in addition to awareness raising activities, and 2 have benefited directly from the testing organised within them for the benefit of the pupils.

$\begin{array}{lll}\begin{array}{l}\text { Political-administrative } \\ \text { authorities (APA) }\end{array} & \text { Collaboration with the BCZS } & \text { Low }\end{array}$

\section{Finding:}

The interviewed ABSs state that they participate in activities upon in vitiation of the UA leaders; what else is a passive role.

\begin{tabular}{l}
$\begin{array}{l}\text { The central offices of the } \\
\text { health zones }\end{array} \begin{array}{l}\text { Supervision of the activities of screening and care } \\
\text { facilities, local organisations and supply of inputs to the } \\
\text { facilities. }\end{array}$ \\
\hline $\begin{array}{l}\text { Finding: } \\
\text { The BCZs get involved according to the means available and the support of the partners. }\end{array}$ \\
$\begin{array}{l}\text { National programmes of the } \\
\text { Ministry of health national } \\
\text { reproductive health program } \\
\text { (PNSR), (national adolescent } \\
\text { health program (PNS), PNLS }\end{array}$ \\
$\begin{array}{l}\text { Finding: } \\
\text { These programmes organise training, make input allocations and at times organise mass campaigns. Awareness-raising } \\
\text { in schools and out-of-school settings (peer communication, dissemination of messages through the media, screening of } \\
\text { films and documentaries in youth centres, HIV screening and biological monitoring of infected adolescents and young } \\
\text { people, training of teachers and inspectors, training of community leaders, participation of health zone officials. These } \\
\text { actors have the support of UNICEF in 'All in project'. All these programmes has low geographic coverage. }\end{array}$ \\
\hline
\end{tabular}


With service providers; according to the providers interviewed, adolescents and young people have prejudices about health services: "they are not convinced of confidentiality and want to receive services in centres where they are not known at all, sometimes they even present themselves under false identities" nurse Katana

Another added : "the existing programmes put a lot of emphasis on young adults, they totally forgot about adolescents and young people, because we thought they were not as high risk as these very sexually active adults, I think it was a mistake, because people's behaviour has changed a lot with, for example, the Ndogo-Ndogo phenomena (relations between young and older people both in men and women), Kishakoshi (relations between older men, especially married men, and adolescent and young girls, here the girl considers the man as her wallet; Chu Cha Chu(proliferation of Nganda where beer, food and a roomservice are offered )." Nurse in the Minova health area.

All these phenomena were reported to us in all the health areas visited, with an increased accentuation in the urban part. Awareness-raising is organised by adults, which means that adolescents and young people do not feel concerned, they prefer activities organised by other young people, but these are rare. "the services do not take into account the young people's schedules, they meet at school while the activities are in progress. When they come out, they can't have the opportunity to have remedial activities, we have to go to other activities. Our interviews with all stakeholders highlight the irregularity of the services offered. Both providers and Health Zone managers attribute this irregularity to the scarcity of resources, and when they are allocated, they are too insufficient to ensure real mobilization of communities and adolescents and young people in particular. For example, the facilities have almost no inputs for screening, for example.

"Sometimes we sporadically sensitise young people, but when we get to the screening stage, we send them to the health facilities, but there are no inputs, the providers say, they send them back to our offices and there, no, we are blocked, but we don't know what exactly to do, it discourages our teams". "This problem of resources is very crucial, the quantity of tests for example that we receive is intended for PMTCT and blood safety, and we are already having difficulty covering these needs in all the health zones; we don't have enough inputs, unfortunately! An health zone manger.

"We no longer feel a commitment from the authorities in this struggle, we can't do it without resources! "said an anonymous teacher. When asked what to do to solve these problems, opinions converge: special attention must be paid to young people and they must be given the resources to organise services that will be adapted to them and easily accessible to them. All the actors say that they are concerned and ready to offer their support: "the struggle must begin with an appropriation by the young people and the authorities before spreading to the rest of us, we must be open, but without compromising, faith has its demands, but the salvation of souls also passes through other useful teachings for young people to avoid sexually transmitted diseases".

"Sex education must start in the family and continue at school, if parents don't do their part, we will always have a hard time helping adolescents and young people, they will take information from the street. For the fight against HIV, I keep asking myself: won't it take special training and resources to do it properly? I believe that this is the key. "a secondary school teacher "we are here to support the actions of the health zones, perhaps also to mobilise the populations, but the resources are not available and frankly, I don't know what more can be expected of us". "Resources have to be mobilised at all levels and really used, at home we have an accountability problem, we have to mobilise resources and really use them". A leader of a civil society organisation. "We don't have a problem, we just have to have the means, we know what to do, but without resources we are limited. How can we screen without inputs? You have to retrain providers, give them resources and motivate them. We also need to federate all the partners in order to know what they are doing and accompany them, because some come and start intervening without informing us of what they are going to do exactly", Manager of one of the health zone.

"It is time for us to be taken into account at all stages of the activities, we want to be actors and not reduced to the level of beneficiaries alone, we want concrete actions that target our priorities and have spaces for discussion without taboos. We want to be involved, there is a saying: "what you do for us without us, you do against us", I believe that this is what is happening, we need to change. All in is already a good start and in my opinion, the other actors should follow suit. "a Kadutu peer educator.

\section{DISCUSSION}

\section{Stakeholders}

Several stakeholders report that they are involved in the fight against HIV among adolescents and young people in the health zones visited. They were grouped into religious denominations (Catholics, Protestants, Kimbanguists and others), local NGOs, health zones and their structures, specialised programmes (PNLS, PNSR and PNMLS).

Main activities are in the field of prevention, including: awareness raising (behaviour change communication), screening, condom distribution and post-exposure prevention for health facilities. The level of involvement of stakeholders was judged to be average. The interventions only partially cover one of the six strategic priorities of the National Strategic Plan to combat AIDS. ${ }^{4}$ 
According to the joint United Nations programme on HIV/AIDS, the needs of young people living with HIV or AIDS as well as those of other adolescents and young people are "underestimated and largely unmet". 5 What remains evident is that the needs of young people in the health zones visited are manifold and require good assessment, planning and participatory implementation that puts the people concerned-adolescents and young people - at the centre of the action. Prevention must be an entry point for access to other services available in the facilities. Indeed, various constraints still undermine these efforts, namely the weakness of coordination, which is reflected in the insufficient alignment and harmonisation of interventions in accordance with the "three ones", the low coverage of the main interventions, the inadequacy of the response to the determinants identified in the priority target groups, etc. ${ }^{6}$ As noted in the results, significant fringes of these stakeholders carry out actions in a sporadic and disparate manner. Some actors intervene without being known to the coordinating bodies. These actions cannot reverse the trend of the global epidemic, nor will they make it possible to achieve the $3^{\text {rd }}$ MDG.

\section{Sources of information and messages disseminated}

The different sources of information identified by the study participants are: churches, families, NGOs, health structures, mass media and social networks. The mass media are a powerful weapon against STIs/AIDS. Media can disseminate information among young people, such as the ABCs of prevention. The Media can also tackle issue such as how to handle unwanted sexual advances, negotiate condom use and redefine what it means to be a 'real man' and others concerns.'

Family, school, magazines, television or friends are not the only sources of information on contraception and sexuality for young people. Interviews with 14-25 year olds show that the Internet is becoming an increasingly important source of information. The information available on the web complements the prevention campaigns which, while encouraging parents to participate actively in sexuality and contraception issues, sometimes underestimate the obstacles adolescents face (mutual reluctance to communicate on the subject, conflictual relationships, etc.) and which prevent the dissemination of clear information. ${ }^{8}$

Today, young people are considered to be primarily responsible for their health and sexual life (choice and number of partners, choice of contraception, protection, etc.). On social networks, they talk about sexuality with relative freedom and also participate in an exchange of knowledge and the dissemination of various information (sexual practices, contraception, abortion, STIs, HIV/AIDS, etc.). ${ }^{8}$ In the case of this study, the family and social networks were singled out, although the content of the messages is not as edifying as one would have wished, there is a need to reframe it by discussing issues that affect the real needs of adolescents.

As far as the family is concerned, the lack of communication between parents and teenagers about sexuality leads to early sexual relations, multipartnerships, clandestine abortions and non-use of condoms. ${ }^{9,10}$ Warnings against unwanted pregnancies and STI/HIV/AIDS should give way to a frank and uninhibited dialogue between adolescents and parents and thus avoid the above-mentioned consequences. ${ }^{11}$

As far as the family is concerned, many studies show the need for parental involvement in reproductive health education for young people and adolescents. Paradoxically, for many parents, socio-cultural burdens make sex a taboo. Talking about sexuality, especially with adolescent girls, becomes a difficult exercise when these young people today need this communication. Several sources point out that communication between parents and adolescent girls is a strategy that would be most effective if put into practice. ${ }^{12}$

As far as social networks are concerned, it should be noted that positive and negative experiences cross, "good plans" as well as "bad plans" are exchanged between Internet users. Hence the need to remain vigilant by seeking to rely on more credible sources. As the use of interviews with doctors (or psychologists) is frequent on the sites and helps to make them more credible in the eyes of young Internet users. These experts then play the game of "moral and scientific guarantor", reassuring the most sceptical young people: "on this site, there are doctors who talk, it's more serious."On sexuality and contraception, there is no lack of information available on the net and it is sometimes contradictory. ${ }^{8}$

As we have seen from the results, the messages disseminated are selective according to religious beliefs or other considerations and do not allow for an open debate, and the issues of sexuality in general and HIV in particular remain taboo. Garth Japhet takes the opposite view: "It is not magical technical solutions; that will alleviate poverty and the spread of disease, but the active involvement of communities that experience these problems. If people are to be empowered for this engagement, they need to be given the information they need and the opportunity for dialogue and debate on the problems they face."

\section{Perception of the services offered and accessibility}

Here, the results highlight several aspects and underline the fact that services are not easily accessible to adolescents and young people due to certain constraints such as: the supply side of the services; the scarcity of activities targeting adolescents and young people, the great distances between the places where the services are offered and the beneficiaries' residences, the nonsegmentation of the target groups during the sessions and 
the schedules not adapted to the availability of the beneficiaries. Despite the undeniable existence of highrisk phenomena such as "Chu Cha Chu", "Ndogo Ndogo" or "Kishakoshi", some providers minimise the risk of HIV among adolescents even though these practices seriously expose them to HIV, hence the refusal of some to integrate them into activities that they consider to be the prerogative of the most sexually active and therefore at risk.

Prevention activities for young people are organised by adults, which limits young people's opportunities to discuss sexuality issues frankly, and finally, the legal age limit for testing prevents adolescents from being screened when in many cases some are already sexually active and should know their HIV status to protect themselves and others. This situation arises because in order to better address sexual and reproductive health and HIV issues among adolescents and young people, peer education is crucial.

Indeed, the role of the peer educator is important. Their local status enables them, if they fulfil their mission adequately, to ensure important results in the prevention of STIs/HIV/AIDS, in optimal conditions including the elimination of psychological and social barriers, which allows them to tackle sensitive issues with confidence. ${ }^{13}$

On the side of adolescents and young people, there is a fear of lack of confidentiality among providers, and prejudice among adults who believe that adolescents who talk about sexuality are considered prostitutes or promiscuous.

It was also noted that other points such as the sharp criticism of condoms by religious leaders, which means that HIV awareness sessions, when they do exist in religious circles, deliberately omit to talk about condoms, thus opening the way for all speculation and false beliefs about their use. It should also be noted that some parents are suspicious and prejudiced against health providers and others who organise HIV prevention activities. They do not encourage their children to attend health or other social services; for girls, in most cases they are not allowed to attend these services at all.

Contrary to the widely held view, education on sexuality and STIs/AIDS prevention does not encourage young people to engage in debauchery. On the contrary, quality programmes help young people to adopt responsible behaviours, delay the first genital intercourse among young people and protect those who are already sexually active from STIs. In order to educate our children to behave responsibly in sexual matters, let us promote dialogue on sexuality in the family and at school, and support the integration and implementation of small education programmes on sexuality, STIs and HIV/AIDS. ${ }^{14}$
In addition, youth-friendly services offer treatment for STIs and access to condoms and help young people become responsible for their sexual and reproductive health. Voluntary and confidential HIV counselling and testing services allow young people to determine their HIV status and to choose safe behaviours, whether they are uninfected or infected ${ }^{7}$.

\section{Possible solutions}

Several possible solutions were proposed by the participants in the focus groups, the other interviewees and the analysis of obstacles: the State must play its role as a regulator, but also as a provider of resources by mobilising and making sustainable and sufficient resources available to all other stakeholders.

This will enable them to set up prevention actions adapted to the needs of adolescents and young people as provided for in the national strategic plan to fight AIDS. In this respect, we believe that the strengthening of all in the areas where it already exists and its extension to new sites remains one of the promising avenues to hope to reverse the trend of the AIDS epidemic among adolescents and young people in South Kivu.

These actions must aim to train providers on the specific needs of adolescents and young people, to provide facilities with inputs to combat HIV using a holistic approach, to remove the age limit for access to testing and to provide specialised programmes (PNMLS, PNLS, PNSR and PNSA) with sufficient resources for regulation: coordination, monitoring, evaluation and supervision of the partners' activities.

Particular emphasis should be placed on the alignment of partners to the nationals programs, multisectorality and strong involvement of political-administrative, customary and religious authorities in innovative approaches in order to take ownership of the response to HIV at the community level.

The regulation of the sale and consumption of highly alcoholic beverages, bordels and a fight against other social phenomena devastating youth: Kishakoshi, ChuCha-Chu, Ndogo-Ndogo and other similar phenomena. The support partners should support the implementation of innovative approaches such as all in by ensuring a duration that is likely to allow ownership and sustainability by communities in general and adolescents and young people in particular by covering the whole province and not just a few health zones as is the case at present. In addition to support in terms of equipment, training and support for the operation of the communitybased organizations (OACs), attention should be paid to supporting the operation of youth centres. 


\section{OACs, Churches, families}

In all these structures, it would be desirable to address the issue of prevention in a comprehensive way without omitting the correct and systematic use of condoms as one of the means of prevention. Of course, the ideal would be to insist on abstinence to encourage adolescents and young people to delay the first sexual intercourse as long as possible, but when this is not possible, they should take appropriate measures to minimize the risk of STIs and unwanted pregnancies.

Interventions targeting adolescents and young people should be user-friendly, offer guarantees of confidentiality and, as far as possible, be organised by their peers. The discourse of warnings about pregnancy, stigmatisation of PLWHIV and prejudice against young people using HIV prevention services must give way to frank, open and well-directed dialogue between adolescents and young people on the one hand and between adolescents and their carers on the other; this will inevitably lead to the adoption of safer behaviours in relation to HIV and sexual and reproductive health.

\section{Adolescents and young people}

As for adolescents and young people, they must stop being mere spectators of their disaster, they must engage in the activities initiated in their favour and, as far as possible, take the lead in proposing actions they deem necessary for their well-being. No one will be able to adopt HIV-friendly behaviours for them. Everything depends on correct information, which forces them to take ownership of the actions that are carried out in their favour and to invest personally in the fight against it.

\section{Limitations}

It is not possible to generalize the results of this study to all adolescents and young people in South Kivu. Moreover, the tendency to avoid being badly perceived leads to conformism to certain meanings commonly accepted by members of the community; this had an impact on sincerity of declarations. Finally, the media realities of rural and urban areas are not identical; they influence the level of information of adolescents and young people in terms of HIV prevention.

\section{CONCLUSION}

The needs of adolescents and young people are not sufficiently met in preventing HIV in our environment due to many constraints: political, organisational, legal, economic-financial, socio-cultural and religious. The services offered do not take into account the vulnerability of this population category to HIV and the emergence of new phenomena and risky behaviours. This implies that there is a long way to go by stakeholders in ensuring inclusive prevention interventions to reverse the current trend of the HIV epidemic among adolescents and young people in South Kivu province.

\section{Funding: No funding sources}

Conflict of interest: None declared

Ethical approval: The study was approved by the Institutional Ethics Committee

\section{REFERENCES}

1. Teenage girls bear brunt of a far-from-over HIV/AIDS epidemic. Available at :https://www. unicef.org/fr/press-releases/every-three-minutesteenage-girl-infected-hiv-unicef. Accessed on 13 July 2020.

2. Hausse des nouvelles infections à VIH. Available at: http://cd.one.un.org/content/unct/rdc/fr/home/actualit es/selon-1_unicef--une-hausse-des-nouvellesinfec tions-par-le-vih-e.html. Accessed on 13 July 2020.

3. DHS report. Available at: https://dhsprogram.com/ publications/publication-fr300-dhs-final-reports.cfm. Accessed on 13 July 2020.

4. PNMLS, Plan stratégique National de lutte contre le Sida. Available at : https://pnmls.cd/. Accessed on 13 July 2020.

5. Joint United Nations Programme on HIV/AIDS (UNAIDS). Available at: http://www.un.org.np/sites/ default/files/2011-08-17-UNAIDSStrategy-en.pdf. Accessed on 26 August 2021.

6. Bahizire R. Mécanismes de survie et modèle de réinsertion socio-économique des personnes vivant avec le VIH dans la ville de Bukavu. Available at : https://reliefweb.int/report/democratic-republiccongo/rd-congo-la-fondation-femme-plus-et-le-bien$\%$ C $3 \%$ AAtre-des-pvv-de-bukavu. Accessed on 13 July 2020.

7. UNICE, UNAIDS, Youg people and HIV/AIDS, opportunity in crisis. Available at: https://www.unaids.org/sites/default/files/media_asse t/youngpeoplehivaids_en_0.pdf. Accessed 13 July 2020

8. Institut National de prévention et d'éducation pour la santé. Avalable at: https:// www.inpes.santé.fr. Accessed on 18 July 2020.

9. Biglan A, Metzler CW, Wirt R, Ary D, Noell J, Ochs L, French C, Hood D. Social and behavioral factors associated with high-risk sexual behavior among adolescents. J Behav Med. 1990;13(3):245-61.

10. Small SA, Luster T. Adolescent sexual activity: an ecological, risk-factor approach. J Marriage Family. $1998 ; 56: 181-92$.

11. Di-Clemente RJ. Parental monitoring and its association with a spectrum of adolescent health riskb ehaviours. Pediatrics. 2001;107:1363-8.

12. Some DT, Some DA, Hien H, Diallo R, Zingue D, Diallo I, Diagbouga S, Dao B. Sexual and reproductive health of adolescent girls in Bo bo Dioulasso, Burkina Faso: the role of parentadolescent communication for risk reduction. Pan Afr Med J. 2012;11:65. 
13. Pair éducateur, Manuel du pair éducateur: techniques de communication interpersonnelle appliquées à la prévention des HIV, 2003. Available at: https://www.unodc.org/pdf/youthnet/action//handbook_peer_frensh.pdf. Accessed on 18 July 2020.

14. PNLS DRC, Training of Trainers Module on HIV/AIDS. Available at: https://pdf.usaid.gov/
pdf_docs/PA00HVGB.pdf, Accessed on 18 July 2020.

Cite this article as: Richard BR, Freud MB, Lambert MAJ, Synthia AM, Fefe MN, David KA, et al.

Prevention of HIV infection among adolescents and young people in South Kivu: challenges and prospectives. Int J Reprod Contracept ObstetGynecol 2021;10:2169-77. 